\title{
MODEL PERMASALAHAN EFEKTIFITAS SISTEM KOORDINASI PELAYANAN KESEHATAN DI RUMAH SAKIT BADAN LAYANAN UMUM DAERAH BAHTERAMAS PROVINSI SULAWESI TENGGARA
}

\author{
Suhadi ${ }^{1}$, Alimin Maidin ${ }^{2}$, Sukri Palutturi ${ }^{3}$, Burhanuddin Bahar ${ }^{4}$, Nurmaladewi $^{5}$, Yasnani $^{6}$, \\ Junaid ${ }^{7}$, La Dupai ${ }^{8}$, Esti Astuty ${ }^{9}$ \\ ${ }^{15678}$ Fakultas Kesehatan Masyarakat, Universitas Halu Oleo, Kendari \\ ${ }^{2}$ Jurusan Manajemen Administrasi Rumah Sakit, Fakultas Kesehatan Masyarakat, Universitas Hasanuddin, \\ Makassar \\ ${ }^{3} J u r u s a n$ Administrasi Kebijakan Kesehatan, Fakultas Kesehatan Masyarakat, Universitas Hasanuddin, Makassar \\ ${ }^{4}$ Jurusan Gizi, Fakultas Kesehatan Masyarakat, Universitas Hasanuddin, Makassar \\ ${ }^{9}$ Rumah Sakit Umum Daerah Bahteramas Prov Sultra. Kendari \\ ${ }^{1}$ suhaditsel77@yahoo.com 2aliminmaidin@gmail.com 33sukritanatoa72@gmail.com \\ 4burhanuddin.bahar@gmail.com 5nurmaladewi9191@gmail.com6yasnani_rahabuddin@yahoo.com \\ 7junaid@yahoo.com8/adupai1954@gmail.com 99estiastutiamsyar@gmail.com
}

\begin{abstract}
Abstrak
Rumah Sakit sebagai lembaga pelayan publik tidak hanya melakukan fungsi bisnis tetapi juga melakukan fungsi sosial bagi masyarakat. Dalam konteks lembaga usaha pelayan publik modern, rumah sakit terus dituntut untuk memaksimalkan pelayanan kesehatan sehingga tercipta pelayanan yang bermutu dan memuaskan pelanggan. Tujuan Penelitian adalah menganalisis efektifitas koordinasi Pelayanan Kesehatan Di Rumah Sakit Badan Layanan Umum Daerah (RS-BLUD) Bahteramas Provinsi Sulawesi Tenggara, menyusun model permasalahan dan solusi masalah efektifitas sistem koordinasi pelayanan kesehatan. Jenis Penelitian kualitatif, dengan menggunakan pendektan studi kasus. Informan penelitian adalah pasien dan petugas RS. Pengumpulan data dengan menggunakan wawancara mendalam, observasi dan telaah dokumen. Hasil penelitian menunjukan umumnya sistem koordinasi pelayanan kesehatan di RS BLUD Bahteramas belum seluruhnya efektif. Dalam pelaksanaannya masih mengalami permasalahan diantaranya kurangnya informasi pada pasien hal koordinasi petugas dalam pelayanan, koordinasi petugas kurang cepat, koordinasi petugas kurang tepat, koordinasi petugas kurang sesuai harapan, dan kurang koordinasi antar petugas. Pelaksanaan sistem koordinasi pelayanan kesehatan di RS BLUD belum sepenuhnya efektif.
\end{abstract}

Kata Kunci: Rumah Sakit, JKN, Sistem Koordinasi, Efektivitas

\begin{abstract}
Hospital as a public service institution not only carries out business functions but also performs social functions for the community. In the context of modern public service business institutions, hospitals are required to maximize health services for high-quality services and customer satisfaction. This study aims to analyze the effectiveness of coordination of Health Services at the Bahteramas Regional Public Hospital (BLUD) Hospital of Southeast-Sulawesi Province, to develop a model of problems and solutions to the effectiveness of the health service coordination system. This is qualitative research, using a case study approach. Research informants are patients and hospital staff. Data collected by using in-depth interviews, observation and document review. The results showed that generally the health service coordination system at Bahteramas BLUD Hospital was not entirely effective. In its implementation, there are still problems including the lack of information for patients in terms of officer coordination on service, the lax of officer coordination, the deficient of officer coordination, the dissatisfaction of officer coordination, and the lack of coordination between officers. The implementation of the health service coordination system at BLUD Hospital has not been fully effective.
\end{abstract}

Keywords: Hospital, JKN, Coordination System, Effectiveness 


\section{PENDAHULUAN}

"Health is a Fundamental Human Right" merupakan konsep World Health Organization (WHO) untuk menjamin agar setiap orang dapat hidup sehat untuk berproduksi. Kepemilikan hak oleh seseorang tersebut secara nyata mencerminkan dua kewajiban mutlak bagi setiap orang atau lembaga yang mengupayakan dan memberikan pelayanan kesehatan yaitu menyehatkan yang sakit dan mempertahankan yang sehat. Sehingga dengan sendirinya menjadi kewajiban setiap negara di dunia untuk menjamin hak tersebut dapat dipenuhi dan diterima oleh seluruh penduduk ${ }^{1}$.

Pemerintah Indonesia sejak tanggal 1 Januari 2014 telah menerapkan Jaminan Kesehatan Nasional bagi seluruh rakyatnya secara bertahap hingga 1 Januari 2019. Melalui penerapan Jaminan Kesehatan Nasional (JKN), diharapkan tidak ada lagi masyarakat Indonesia, khususnya masyarakat miskin yang tidak berobat ke fasilitas pelayanan kesehatan di kala sakit karena tidak memiliki biaya. Jaminan ini disebut Jaminan Kesehatan Nasional karena semua penduduk Indonesia wajib menjadi peserta jaminan kesehatan yang dikelola oleh Badan Penyelenggara Jaminan Sosial (BPJS) termasuk orang asing yang telah bekerja paling singkat enam bulan di Indonesia dan telah membayar iuran².

Kualitas pelayanan dalam industri pelayanan kesehatan merupakan hal yang sangat penting dalam mewujudkan kepuasan pelanggan, apalagi hal ini berhubungan dengan hidup mati seseorang. Di dalam lingkungan yang semakin penuh dengan persaingan, rumah sakit mesti semakin sadar tentang perlunya memberikan kualitas pelayanan yang terbaik bagi pelanggannya. Kualitas pelayanan didefinisikan sebagai perbedaan antara harapan pelanggan dengan kenyataan yang diterima ${ }^{3}$. Kepuasan merupakan pernyataan psikologi yang dihasilkan dari terpenuhi atau tidaknya harapan dengan pelayanan yang diterima secara nyata ${ }^{4,5}$. Industri jasa merupakan sebuah sektor yang berbeda dibanding dengan sektor manufaktur. Salah satu contoh daripada sektor jasa ialah industri pelayanan kesehatan misalnya rumah sakit. Dalam industri perawatan kesehatan, rumah sakit menyediakan jenis-jenis pelayanan yang sama, tetapi mereka tidak menyediakan kualitas pelayanan yang sama ${ }^{6}$. Sedangkan, pelanggan sekarang lebih cerdas untuk memilih alternatif-alternatif yang ditawarkan dan meningkatkan tingkat pelayanan yang telah menaikkan harapan mereka. Dalam industri pelayanan kesehatan, pasien merupakan pelanggan dan ia merupakan bagian yang sangat penting dalam perkembangan industri kesehatan ini.

Menurut Strerss ${ }^{7}$ efektifitas adalah jangkauan usaha suatu program sebagai suatu sistem dengan sumber daya dan sarana tertentu untuk memenuhi tujuan dan sasarannya tanpa melumpuhkan cara dan sumber daya itu serta tanpa memberi tekanan yang tidak wajar terhadap pelaksanaannya. Menurut Gibson ${ }^{8}$ bahwa faktor yang mempengaruhi efektifitas adalah Ciri organisasi, Ciri lingkungan, Ciri pekerja Kebijakan dan praktek manajemen.

Hasil obsevasi awal yang dilakukan pada pelayanan kesehatan di RS BLUD Bahteramas Prov. Sultra diperoleh beberapa permasalahan berupa lambatnya pelayanan, waktu tunggu yang lama, tidak adanya koordinasi pelayanan, dan berbelitnya pelayanan. Tujuan penelitian untuk menganalisis efektifitas sistem koordinasi pelayanan kesehatan di RS BLUD Bahteramas Prov. Sultra, menyusun model permasalahan dan solusi masalah efektifitas sistem koordinasi pelayanan

\section{METODE}

Jenis penelitian kualitatif, dengan pendekatan studi kasus. Informan adalah pasien dan Petugas RS Bahteramas. Pengumpulan data dengan menggunakan observasi, wawancara mendalam dan telaah dokumen. Analisis data dengan menganalisis permasalahannya dilakukan secara deskriptif, yang lebih menekankan analisisnya pada proses penyimpulan terhadap dinamika antar fenomena yang diamati, dengan menggunakan logika dan cara-cara berfikir formal dan argumentatif ${ }^{9}$.

\section{HASIL DAN PEMBAHASAN}

Hasil temuan wawancara mendalam diperoleh bahwa dalam hal koordinasi petugas pelayanan, pasien menyatakan bahwa tidak ada koordinasi yang baik antar petugas dan bagian rumah sakit dalam hal masalah pelayanan obat, dan status rekam medis, terkadang pasien harus bolak balik berurusan dari satu loket ke loket lain sehingga kondisi ini seringkali menghambat pelayanan walaupun fungsi koordinasi pelayanan tersebut tetap dilakukan oleh petugas, sebagaimana pernyataan beberapa informan berikut ini:

„,, untuk layanan aah cepat kalau koordinasi nya saya lihat bagus iya kalau mau dibilang cepat tergantung kadang kan dari itu kartu ditampung dulu dari sana baru bisa di bawa dikadang dipoli 
kalau mau di bilang cepat ya tergantung ,, (NBH, 24 Tahun)

„, koordinasi tidak ada pak misalnya, masalah obat, dokter sudah resepkan, saya ke apotik, obatnya tidak ada, saya balik lagi kepoli, dokter buatkan resep baru,,disini kita kayak dipimpong, seharusnya dokter telpon dulu apotik apa obat ini tersedia klo diresepkan „, (NNI 32 Tahun)

,') ada berfungsi kordinasi tentang seumpama contoh keterlambatan map pasien saya yang hubungi ke sana ke RM menelpon kadang lewat HP ,, (NMA 53 Tahun)

Hasil temuan wawancara mendalam diperoleh bahwa dalam hal kecepatan koordinasi pelayanan pasien menyatakan bahwa masih terdapat keterlambatan koordinasi yang disebabkan oleh faktor jarak antar bagian rumah sakit yang jauh dan alat komunikasi yang terganggu (rusak). Dalam hal ketidaktepatan koordinasi pelayanan, ketidaktepatan disebabkan oleh faktor ketidaktelitian petugas, dan kekurang pahaman pasien dalam menulis status rekam medis, sebagaimana pernyataan beberapa informan berikut ini:

',' cukup lama, katanya kartunya masih dicari belum sampai kesini ,,, (WMU 54 tahun)

,, keterlambatan koordinasi biasanya, jarak yang jauh pak ,,, (SYN 49 tahun)

„, lamanya koordinasi itu pak, disini earphone rusak, gak berfungsi,,, (NMA 53 Tahun)

Dalam hal koordinasi pelayanan kesehatan di rumah sakit diperoleh bahwa masih ada keluhan pelayanan kesehatan pada pelayanan Rumah Sakit Bahtramas Prov Sultra, sebagaimana keluhan tersebut secara jelas tergambar dalam bagan 1 berikut ini:

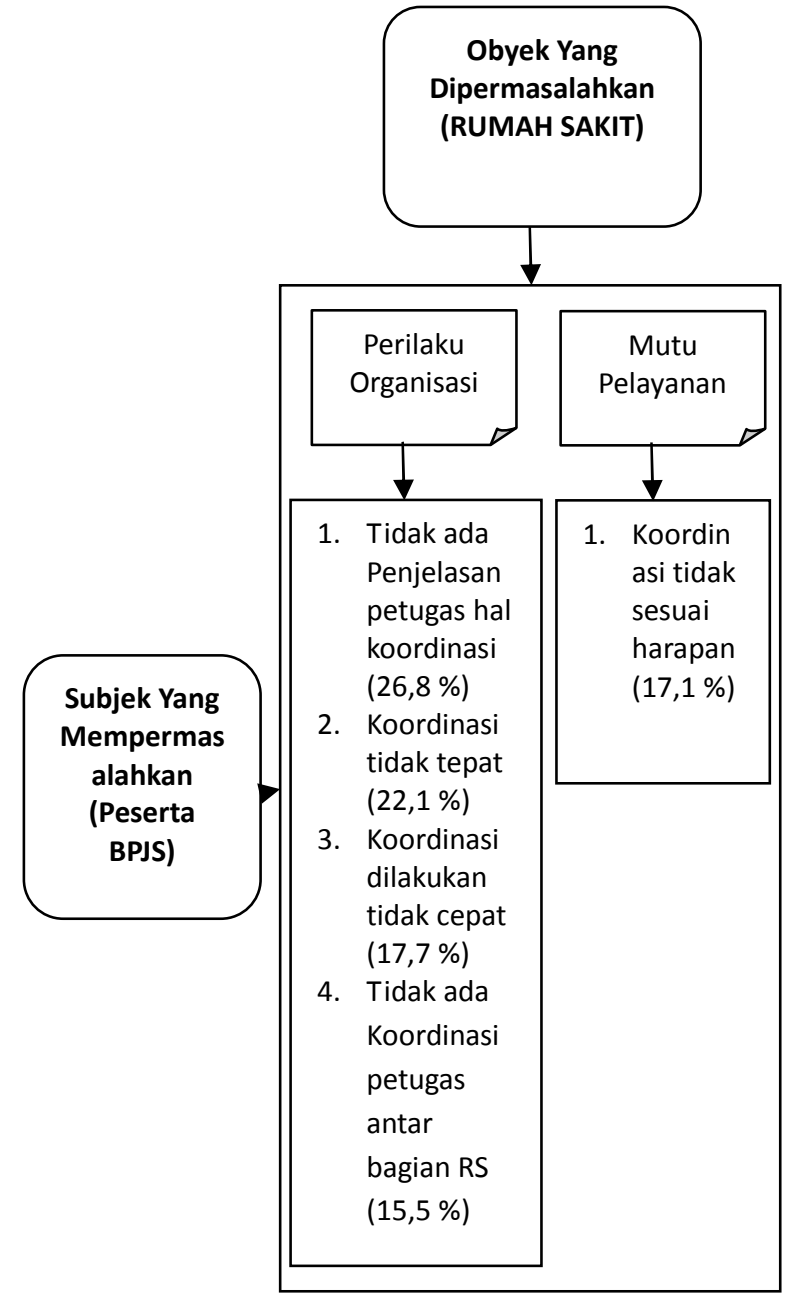

Bagan 1. Model Permasalahan Sistem Koordinasi Pelayanan Kesehatan Rumah Sakit Bahteramas Prov. Sultra

Menurut Hasibuan ${ }^{10}$ koordinasi adalah kegiatan mengarahkan, mengintegrasikan, dan mengkoordinasikan unsur-unsur manajemen dan pekerjaan-pekerjaan para bawahan dalam mencapai tujuan organisasi. Sedangkan faktor yang mempengaruhi koordinasi, kesatuan tindakan, komunikasi, pembagian kerja, dan disiplin. Menurut Sondang ${ }^{11}$ cara-cara yang dapat dilakukan dalam mengkoordinasi, yaitu dengan melakukan briefing staf untuk memberitahukan kebijaksanaan pimpinan organisasi kepada staf yang dalam waktu sesingkat mungkin harus diketahui dan mendapat perumusan.

Koordinasi petugas yang lambat/kurang /tidak ada, hal ini menyusahkan pasien dalam mendapatkan pelayanan bahkan tidak jarang pasien harus lama menunggu, stres, gerah, marah, kecewa dan terkadang pasien harus bolak balik berurusan dari satu loket ke loket lain misalnya dalam hal pelayanan obat, dan status rekam medis. 
Olehnya itu hendaknya pihak rumah sakit melakukan pengawasan dan perbaikan koordinasi pelayanan baik melengkapi sumber daya yang kurang, penyatuan pelayanan secara terpadu maupun pelayanan interkoneksitas sistim informasi disediakan rumah sakit.

Tidak adanya koordinasi antara petugas RS sehingga menyebabkan terhambatnya pelayanan kesehatan. Sebaliknya koordinasi yang terjalin baik akan menguntungkan pelayanan kesehatan, sebagaimana hasil penelitian sebelumnya ${ }^{12}$ bahwa koordinasi berhubungan dengan Produktivitas Kerja pegawai. Penelitian lainnya ${ }^{13}$ menunjukkan bahwa kerjasama menjadi salah satu titik penting dalam meningkatkan kualitas pelayanan Rumah sakit. Penelitian lain ${ }^{14}$ juga menunjukkan bahwa koordinasi internal yang dilaksanakan kurang terlaksana dengan baik dalam mengatasi keluhan pelanggan khususnya masalah ketepatan waktu pelayanan pelanggan yang sering terlambat dan penanganan tidak dilaksanakan dengan baik sehingga berpengaruh terhadap kepuasan pelanggan.

Ketidakcepatan koordinasi pelayanan akan menghambat pelayanan maka hal ini akan membuat pasien gelisah menunggu pelayanan, gerah dengan lambatnya pelayanan, bahkan kecewa bila hal ini sering terjadi ketika setiap kali pasien mengunjungi pelayanan tersebut. Olehnya itu perlunya rumah sakit melakukan perbaikan manajemen pelayanan dalam hal koordinasi pelayanan dengan memperbaiki saluran komunikasi dan mendekatkan jarak antar bagian rumah sakit sehingga tercipta kecepatan pelayanan. Demikian juga dalam hal ketidaktepatan koordinasi pelayanan, perlunya memperbaiki ketidaktelitian petugas, dan memberi pemahaman pasien dalam menulis status rekam medis

Penelitian Kartina dkk $^{15}$ bahwa koordinasi internal kurang terlaksana dengan baik, sehingga banyaknya keluhan pelanggan masalah ketepatan waktu pelayanan sering terlambat dan penanganan tidak dilaksanakan dengan baik sehingga berpengaruh terhadap kepuasan pelanggan. Penelitian sebelumnya ${ }^{15}$ menunjukkan bahwa koordinasi dan pengarahan berjalan bersama dari tercapainya tujuan yang ditetapkan.

\section{Model Permasalahan Sistem Koordinasi Pelayanan Rumah Sakit}

Koordinasi merupakan daya upaya untuk mensinkronkan dan menyatukan tindakan-tindakan kelompok tugas dalam suatu manajemen. Koordinasi (coordination) mengandung makna menjaga agar tugas-tugas yang telah dibagi, tidak dikerjakan menurut kehendak yang mengerjakan saja, tetapi menurut aturan sehingga menyumbang penyampaian tujuan. Koordinasi itu sangat penting dalam suatu organisasi, adapun faktor yang membuat koordinasi itu menjadi penting adalah Untuk mencegah terjadinya kekacauan, percekcokan, dan kekembaran atau kekosongan pekerjaan, Agar orang-orang dan pekerjaannya diselarasikan serta diarahkan untuk pencapaian tujuan perusahaan, Agar sarana dan prasarana dimanfaatkan untuk mencapai tujuan, Supaya semua unsur manajemen (6M) dan pekerjaan masing-masing individu karyawan harus membantu tercapainya tujuan organisasi, dan Supaya semua tugas, kegiatan, dan pekerjaans terintegrasi kepada sasaran yang diinginkan.

Berdasarkan gambar diatas, maka didapatkan model permasalahan dan solusi masalah sistem koordinasi Pelayanan kesehatan pada Rumah Sakit Bahtramas Prov Sultra adalah sebagai berikut:

1. Subyek yang mempermasalahkan

Subyek merupakan orang yang terlibat langsung dalam pelayanan kesehatan dalam hal ini pasen jamkesmas (PBI) dan pasien mandiri yang menerima pelayanan kesehatan di rumah sakit BLUD Bahtramas Prov Sultra. Pasien jamkesmas dan mandiri disini sebagai orang yang mempermasalahkan langsung pelayanan kesehatan yang telah diterimanya.

2. Objek yang dipermasalahkan

Objek merupakan Rumah Sakit atau petugas yang terlibat langsung dalam penyediaan pelayanan kesehatan. Petugas dan pihak Rumah sakit disini sebagai pihak yang dipermasalahkan secara langsung atas penyediaan pelayanan yang telah dilakukannya pada pasien jamkesmas dan mandiri

3. Jenis pelayanan yang dipermasalahkan

Jenis pelayanan yang dipermasalahkan merupakan usaha/tindakan pelayanan yang telah dikerjakan oleh petugas/RS dalam rangka pemenuhan pelayanan kesehatan.

Dalam hal koordinasi Pelayanan kesehatan, jenis pelayanan yang dipermasalahkan oleh pasien jamkesmas dan mandiri adalah sebagai berikut ;

a. Perilaku organisasi

Perilaku petugas/organisasi adalah sebuah tindakan yang konkret yang ada pada diri manusia berupa sebuah tanggapan dan reaksi dari manusia tersebut yang berbentuk atau yang terwujud dari individu berupa suatu sikap dan tindakan anggota yang membentuk perilaku organisasi sehingga melahirkan budaya kerja yang telah menjadi panutan tindakan dalam pelayanan kepada publik. 
Perilaku organisasi yang diharapkan dalam pelayanan publik adalah perilaku yang dapat mendukung dan membentuk terciptanya pelayanan yang memuaskan pelanggan.

Masih adanya keluhan pasien akan Perilaku petugas dalam hal koordinasi pelayanan berupa tidak ada Penjelasan petugas dalam hal koordinasi $(26,8 \%)$, koordinasi tidak tepat $(22,1 \%)$, lambatnya koordinasi pelayanant $(17,7 \%)$, dan tidak adanya koordinasi petugas antar bagian RS $(15,5 \%)$, hal ini menunjukkan bahwa dalam hal koordinasi pelayanan masih terdapat permasalahan, oleh karena itu perlunya pihak manajemen BPJS untuk melakukan perbaikan perilaku petugas melalui pelatihan dan pengawasan agar pelayanan yang diberikan dapat berjalan secara cepat dan tepat serta terhindar dari tentundanya pelayanan kesehatan

b. Mutu pelayanan

Kualitas di atas dapat disimpulkan bahwa kualitas pelayanan publik merupakan suatu kondisi dimana pelayanan mempertemukan atau memenuhi atau bahkan melebihi dari apa yang menjadi harapan konsumen dengan sistem kinerja aktual dari penyedia jasa. Keberhasilan proses pelayanan publik sangat tergantung pada dua pihak yaitu birokrasi (pelayan) dan masyarakat (yang dilayani). Dengan demikian untuk melihat kualitas pelayanan publik perlu diperhatikan dan dikaji dua aspek pokok yakni: pertama, aspek proses internal organisasi birokrasi (pelayan); kedua, aspek eksternal organisasi yakni kemanfaatan yang dirasakan oleh masyarakat pelanggan.

Masih adanya keluhan pasien dalam hal koordinasi pelayanan berupa koordinasi tidak sesuai harapan $(17,1 \%)$, hal ini menunjukkan bahwa mutu koordinasi pelayanan masih menjadi permasalahan, oleh karena itu perlunya perbaikan manajemen pelayanan oleh pihak RS melalui pelatihan majanemen pelayanan maupun pengawasan pelayanan untuk memastikan pelayanan tersebut telah berjalan baik dan dan terhindar dari keterlambatan pelayanan, sehingga berbagai hambatan pelayanan di masa datang tidak terulang lagi.

\section{SIMPULAN DAN SARAN}

Simpulan

1. Pelaksanaan sistem koordinasi pelayanan kesehatan di RS BLUD belum sepenuhnya efektif.

2. Dalam pelaksanaannya masih mengalami permasalahan diantaranya kurangnya informasi pada pasien hal koordinasi petugas dalam pelayanan, koordinasi petugas kurang cepat, koordinasi petugas kurang tepat, koordinasi petugas kurang sesuai harapan, dan kurang koordinasi antar petugas.

Saran

1. Perlunya Pihak RS melakukan perbaikan kebijakan, respon cepat terhadap pelayanan, pengawasan dan evaluasi sistem pelayanan.

\section{DAFTAR PUSTAKA}

1. Maidin, Alimin. (2013). Ekonomi dan Pembiayaan Sektor Kesehatan. Makassar: Masagena Press.

2. Kemenkes Republik Indonesia. (2013). Buku Saku FAK Badan Penyelenggara Jaminan Sosial Kesehatan. Jakarta: Sekretariat Jendral.

3. Parasuraman, Etc. (1985). A conceptual model of service quality and its implications for future research. Journal of Marketing, 49(3), 41-50.

4. Jackson, etc. (2001). Predictors of Patients Satisfaction. Social Science.

5. Weingarten, et all. (1995). A Study of Patients Satisfactions and adherence to preventive care practice guidelines. The American Journal of Medicine, 99, 590-596.

6. Youssef, et.all. Service Quality in NHS Rumah sakit. Journal of Management in Medicine, 9(1), $66-74$.

7. Sterss, R M. (2005). Efektivitas Organisasi. Terjemahan Magdalena Jamin. Jakarta: Erlangga.

8. Gibson, I D. (2006). Organisasi dan Manajemen: Prilaku Struktur Proses. Jakarta: Erlangga.

9. Consuelo, S G. (1997). Pengantar Metodologi Penelitian. Jakarta: Universitas Indonesia.

10. Hasibuan, M. (2006). Manajemen Dasar, Pengertian dan Masalah. Jakarta: Bumi Aksara.

11. Sondang, P S. (1991). Administrasi Pembangunan. Jakarta: Gunung Agung.

12. Wahyuni, S. (2013). Peranan Koordinasi Terhadap Produktivitas Kerja Pegawai Pada Kantor Dinas Pekerjaan Umum Provinsi Kalimantan Timur.

13. Putra, W. (2012). Efisiensi Dan Efektivitas Pelayanan Rumah Sakit Setelah Pemekaran Wilayah. Journal of Economics and Policy, 5(2), 127-229.

14. Katrina dkk. (2013). Coordination Role in the Office of Regional Water Works (RWW) of Merauke Regency in Serving the Customers Makassar. pasca.unhas.ac.id/jurnal/.

15. Darmawansyah dkk. (2013). Application Management Function In Minasa Upa Public 
Health Center Makassar City. ejournal

Unhas.ac.id. 